\title{
Electrochemical Characterisation of an Os (II) Conjugated Polymer in Aqueous Electrolytes
}

Timothy McCormac ${ }^{1 *}$, John F. Cassidy**, Karl Crowley ${ }^{\star *}$, Lise Trouillet ${ }^{\star \star *}$, Frédéric Lafolet $^{* * *}$, Stephane Guillerez ${ }^{* * *}$

CREATE "Centre for Research in Electroanalytical Technology"

Department of Applied Science

Institute of Technology Tallaght

Tallaght

Dublin 24

Ireland

\section{Abstract}

The electrochemical behaviour of an Os (II) complex of the structurally well-defined conjugated polymer alternating regioregularly alkylated thiophene and 2,2'-bipyridine units (P4Os) has been elucidated in aqueous solution. In typical aqueous electrolyte systems the cyclic voltammogram of the resulting P4Os film exhibits a one electron reversible process corresponding to the $\mathrm{Os}^{3+/ 2+}$ redox system. However the observance of this reversible couple did depend upon the concentration of the supporting electrolyte. It was found that the $\mathrm{Os}^{3+}$ form did form ion-pairs with an anion from the electrolyte solution. Preliminary investigations into the homogeneous charge transport dynamics associated with this redox couple have been undertaken. The technique of cyclic voltammetry, and hence the Randles-Sevick expression, in conjunction with platinum microelectrodes have been employed to determine the $\sqrt{D_{C T}} c$ value.

${ }^{*}$ to whom correspondence should be addressed

** School of Chemistry, Dublin Institute of Technology, Kevin Street, Dublin 8, Ireland 
*** Laboratoire d'Electrochimie Moleculaire et Structures des Interfaces, UMR 5819 CEA-

CNRS-Univ. Grenoble 1, CEA-Grenoble, 17 rue des Martyrs, 38054 Grenoble cedex 09

\section{France}

${ }^{1}$ ISE member 


\section{Introduction}

Conducting polythiophenes have received interest recently due to their possible application in fields such as sensors and light emitting diodes. In particular there is widespread interest in the properties of $\pi$-conjugated polymers that contain redox active or photoactive transition metals. The ability of these metallic centres to interact strongly with the $\pi$-conjugated backbone has been studied [1-4]. Several systems have been explored, such as where the metallic centre is covalently grafted off the main polymer chain with alkyl spacer groups of varying lengths being utilised to distance the metal centre from the chain. An example of this type of system is that the one studied by Zotti et al [5], that is, ferrocene substituted polythiophenes. Of more recent interest is the ability to produce "processable polythiophenes" which exhibit enhance conductivities, whereby the polymer backbone is "connected directly" to coordinated metal centres [6]. The resulting materials have shown enhanced properties primarily due to the fact that there is "no disruption in the conjugation structure". In this contribution we report on the employment of cyclic voltammetry in the study of the charge transport dynamics of a $\pi$-conjugated polymer that consists of a regioregular 3-octylthiophene oligomer alternating with the metal-chelating unit 2,2'bipyridine-5,5'-diyl, through which the $\mathrm{M}(\mathrm{bpy})_{2}{ }^{2+}$ units are coordinated, where $\mathrm{M}$ is $\mathrm{Ru}^{2+}, \mathrm{Os}^{2+}$ [7-9]. To the best of our knowledge this is the first time such an investigation has been undertaken for this material. 


\section{Experimental}

\subsection{Materials}

P4Os (fig 1) was synthesised as described previously [7]. All other chemicals were used as received.

\subsection{Apparatus and Procedures}

A single compartment three-electrode cell was employed for all electrochemical experiments. For the aqueous electrochemical measurements the reference electrode employed was an $\mathrm{Ag} / \mathrm{AgCl}$ aqueous electrode with a teflon shrouded vitreous carbon $\left(\mathrm{A}=0.0707 \mathrm{~cm}^{2}\right)$ disc as a working electrode along with a platinum wire as the auxiliary. For electrochemical experiments in organic media the reference electrode employed was that of a silver wire in contact with an acetonitrile solution of $\mathrm{AgNO}_{3}(0.01 \mathrm{M})$ and $0.1 \mathrm{M}$ of the supporting electrolyte employed in the cell. The carbon working electrode was polished first with $0.05 \mu \mathrm{m}$ alumina, after which it was washed thoroughly with deionised water and acetone prior to use. For the measurements of the parameter $\sqrt{D_{C T}} c$ a $50 \mu \mathrm{m}$ radius platinum microelectrode was employed as the working electrode. This electrode was polished with 1.0, 0.3 and $0.05 \mu \mathrm{m}$ alumina, rinsed thoroughly in deionised water and acetone before being used. A CH 660A potentiostat was employed for all electrochemical experiments. All solutions were degassed with pure argon for 10 minutes prior to electrochemical experiments. All voltammetric experiments were carried out at room temperature. Spectroelectrochemistry of the P4Os film on a platinum macro electrode was recorded using a EG \&G Princeton Applied Research Model 362 scanning potentiostat with an Ocean optics incs2000 fiber optic spectrometer fitted with an Ocean optics tungsten halogen light.

\section{Modified Electrode Preparation}

A small amount of the P4Os polymer was dissolved in a volatile solvent, such as, acetonitrile. Typically $1-2 \mu$ l of this solution was then micropipetted onto the working electrode's surface. The film was ready for electrochemical measurement once the acetonitrile had evaporated. 


\section{Results and Discussion}

\subsection{Electrochemical Characterisation of Thin Films}

The basic electrochemical behaviour of P4Os films on electrode surfaces has previously been investigated [7]. Figure 2(a) illustrates the cyclic voltammogram for a P4Os film in $0.1 \mathrm{M}$ tetrabutylammonium perchlorate (TBAP) in acetonitrile (MeCN) solution. What is apparent is the presence of two nearly overlapping one electron redox processes with $E_{1 / 2}$ values of +0.726 and $+0.754 \mathrm{~V}$ ( $\mathrm{vs} \mathrm{Ag} / \mathrm{AgCl}$ ). The former is associated with the $\mathrm{Os}^{2+/ 3+}$ couple and the latter is due to the first thiophene $\mathrm{PP}^{0 / 1+}$ redox system. Figure 2(b) illustrates the cyclic voltammogram obtained when the $\mathrm{CV}$ is extended further positive so as to include the second thiophene polymer based one-electron oxidation, $\mathrm{PP}^{1+/ 2+}$, with a $\mathrm{E}_{\mathrm{p}, \mathrm{a}}$ of $+1.052 \mathrm{~V}$. These results agree with previous work carried out on the structurally identical P4Ru [9] which showed that scanning the potential of the working electrode through the second thiophene oxidation leads to a substantial loss of conductivity and dissolution of the polymer from the electrode surface.

One objective of this work was to investigate the electrochemical behaviour of the $\mathrm{P} 4 \mathrm{O}$ s polymer in aqueous electrolytes. To the best of our knowledge this has not been undertaken for this polymer. Figure 2(c) illustrates the cyclic voltammogram obtained for a deposited P4Os film on a carbon macroelectrode in $1.0 \mathrm{M} \mathrm{NaNO}$ aqueous solution. Upon continuous scanning between these potential limits the cyclic voltammogram just shows what is believed to be the reversible one-electron redox process associated with the $\mathrm{Os}^{2+}$ centre. To elucidate if the single redox process within the polymer film is associated with the redox switching of the $\mathrm{Os}^{2+}$ centre the electrochemical behaviour of the parent polymer P4 was undertaken in the same aqueous electrolyte system as that in figure 2(c). What was found was that this polymer exhibited no redox activity in this aqueous electrolyte within the same electrochemical window. As the only difference between the structures of the P4 and P4Os polymers is that the latter contains a coordinated $\left[\mathrm{Os}(\mathrm{bpy})_{2}\right]^{2+}$ unit, one can conclude that the single redox wave observed in figure 2(c) is that of the $\mathrm{Os}^{2+}$ centre. 


\subsection{Spectroelectrochemistry}

In-situ spectroelectrochemical experiments were performed on the P4Os polymer to determine the origin of the single redox process observed in Figure 2(c). The procedure involved recording spectra at a variety of electrode potentials between 0.0 and $+1.1 \mathrm{~V}$, then upon re-reduction back to $0.0 \mathrm{~V}$. Before this the film was cycled in $1 \mathrm{M} \mathrm{LiClO}_{4}$ until the single redox process as seen in figure 2(c) was observed. An absorption spectrum of the film was then first obtained at $0 \mathrm{~V}$, the polymeric film was then oxidised in $0.1 \mathrm{~V}$ increments for 60 seconds up to $1.1 \mathrm{~V}$ with simultaneous recording of absorption spectra of the film. Figure 3 shows the resulting spectra obtained before and after the film is oxidised to $+1.1 \mathrm{~V}$ (vs $\mathrm{Ag} / \mathrm{AgCl}$ ) in an aqueous $1 \mathrm{M} \mathrm{LiClO}_{4}$ solution. $\left[\mathrm{Os}(\text { bipy })_{3}\right]^{2+}$ exhibits a band around $500 \mathrm{~nm}$, the presence of this band in the spectrum of the P4Os polymer at $\mathrm{OV}$ is clearly visible. Upon oxidation to $+1.1 \mathrm{~V}$ for 5 minutes there is a clear decrease in this absorbance which can be explained by the fact that at this potential $\mathrm{Os}^{2+}$ is being oxidized to $\mathrm{Os}^{3+}$. Oxidation of the polymer backbone would give a characteristic band around $750 \mathrm{~nm}$, this is clearly not the case for the behaviour of the P4Os polymer in aqueous solution. In addition these spectral changes were found to be reversible in nature. These results clearly point to the identity of the single redox wave for the $\mathrm{P} 4 \mathrm{O}$ s film in aqueous electrolyte can be assigned to the $\mathrm{Os}^{3+/ 2+}$ system of the coordinated Os(bpy $)_{3}{ }^{2+}$ moiety.

\subsection{Electrolyte Effects on Electrochemical Behaviour}

When the redox composition of the P4Os film is switched between the $\mathrm{Os}^{2+}$ and $\mathrm{Os}^{3+}$ states, charge compensating counterions must move between the aqueous electrolyte and the polymer matrix so as to maintain electroneutrality. The ability to redox switch the polymer in various aqueous electrolytes was investigated whereby the nature of the electrolyte was changed. Poor electrochemical responses for the $\mathrm{Os}^{3+/ 2+}$ redox system were obtained in both $\mathrm{NH}_{4} \mathrm{PF}_{6}$ and $\mathrm{KF}$, whilst $1 \mathrm{M} \mathrm{KCl}$ gave an $\mathrm{E}_{1 / 2}$ value of $+0.883 \mathrm{~V}$, but at $100 \mathrm{mVs}^{-1}$ the $\Delta \mathrm{E}_{\mathrm{p}}$ in this electrolyte was measured to be $120 \mathrm{mV}$. This is probably due to electrostatic repulsions 
within the polymer matrix. Further information regarding the electrochemical behaviour of the solid material on the electrode surface can be obtained by investigating the effect of the concentration of the supporting electrolyte on the voltammetry of the P4Os polymer. Information that can be obtained from this data is whether or not ion-pairing exists, the stability of the both the oxidised and reduced forms of the polymer redox site, and if the polymeric film under study possesses high or low permeability towards ionic species from the contacting electrolyte. The parameter of interest is the $E_{1 / 2}$ value of the redox couple under study for the polymer, in our case that associated with the $\mathrm{Os}^{3+/ 2+}$ redox couple. Nernst plots for the variation in $E_{1 / 2}$ with electrolyte concentration for both aqueous $\mathrm{KNO}_{3}$ and $\mathrm{LiClO}_{4}$ yielded slopes of -43.5 and $-42.8 \mathrm{mV}$, respectively. These values are close to the expected $59 \mathrm{mV}$ per decade change in the electrolyte concentration. Previously deviations away from the ideal Nernst values have been stated to be due to "solution ionic strength" or "liquid junction effects" [10]. It is clear that upon increasing the electrolyte concentration the $E_{1 / 2}$ value moves to less positive potentials, this means that the $\mathrm{Os}^{3+}$ redox state form and an electrolyte ion form ion-pairs, as has been stated previously [10].

\subsection{Homogeneous Charge Transport}

Platinum microelectrodes have been employed, in conjunction with cyclic voltammetry, to elucidate the homogeneous charge transport dynamics of the immobilised P4Os film in aqueous electrolytes. An important aspect with regard to the employment of microelectrodes is that "ohmic effects" are eliminated. If the cyclic voltammogram of the polymer film possesses a peak to peak separation $\left(\Delta \mathrm{E}_{\mathrm{p}}\right)$ of close to the theoretical value of $59 \mathrm{mV}$ for a one-electron process and that the peak potentials are independent of scan rate then the Randles-Sevcik equation, stated below, can be applied to our system.

$$
i_{p}=\left(2.69 \times 10^{5}\right) n^{3 / 2} A D_{C T}^{1 / 2} C v^{1 / 2}
$$

where $A$ is the electrode area, $n$ is the number of transferred electrons, $C$ is the concentration of osmium sites within the film and $D_{C T}$ is the homogeneous charge transport diffusion coefficient. Figure 4(a) shows the cyclic voltammograms obtained for a P4Os film in $1.0 \mathrm{M}$ 
$\mathrm{KNO}_{3}$ at various scan rates with table 1 summarising the electrochemical parameters obtained from the individual cyclic voltammograms. What is apparent is that the $E_{1 / 2}$ is independent of scan rate over a large range and therefore the employment of the RandlesSevick equation is justified for the calculation of the product $\sqrt{D_{C T}} C$. The independence of the peak potentials and the $\mathrm{E}_{1 / 2}$ of the $\mathrm{P} 4 \mathrm{O}$ s film was also observed in $1.0 \mathrm{M} \mathrm{LiClO}_{4}$. Figure 4(b) shows the resulting Randles-Sevick plot for the P4Os film in $1.0 \mathrm{M} \mathrm{LiClO}_{4}$ for both the anodic and cathodic branches. For diffusion controlled processes if a plot of $\log i_{p} v s$. $\log v$ is constructed, theoretically the slope should be 0.5 . When this was undertaken for both the anodic and cathodic branches from figure $4(b)$ the slope values of these plots were 0.560 and 0.582 , respectively. From the slopes of the plots in figure $4(\mathrm{~b})$, values of $4.82 \times 10^{-9}$ and 5.11 $\times 10^{-9} \mathrm{~mol} \mathrm{~cm}^{-2} \mathrm{~s}^{-1 / 2}$ were obtained for the $\sqrt{D_{C T}} C$ factors for both the anodic and cathodic branches respectively. This similarity between the oxidation and reduction based $\sqrt{D_{C T}} C$ values points to the fact that the perchlorate anion can pass in and out of the film rapidly, in other words, the film exhibits characteristics of being able to conduct ionic species through its matrix. A tentative value for the effective site concentration of the $\mathrm{Os}^{2+}$ sites within the polymer film was calculated to be approximately $0.036 \mathrm{M}$. This was found from a knowledge of the film's surface coverage $(\Gamma)$, typically between $1.5-2.5 \times 10^{-9} \mathrm{~mol} \mathrm{~cm}^{-2}$, the polymer's molecular weight $(27,588 \approx 16$ monomer units) and the polymer's density $(0.98 \mathrm{~g}$ $\mathrm{cm}^{-3}$, measured by flotation). This yielded a $D_{C T}$ value for the polymer in $1.0 \mathrm{M} \mathrm{LiClO}_{4}$ of $1.8 \mathrm{x}$ $10^{-8} \mathrm{~cm}^{2} \mathrm{~s}^{-1}$. Preliminary work has been undertaken into the effect of the nature and concentration of the supporting electrolyte upon the measured $D_{C T}$ values. The cyclic voltammetric behaviour of P4Os films immobilised on a Pt microelectrode was investigated in both $1.0 \mathrm{M}$ and $0.1 \mathrm{M} \mathrm{KNO}$ electrolyte. The measured $D_{C T}$ values were found to be $8.4 \mathrm{x}$ $10^{-8}$ and $1.0 \times 10^{-8} \mathrm{~cm}^{2} \mathrm{~s}^{-1}$, respectively. These results show that both the nature and the concentration of the charge compensating anion in the background electrolyte has an effect upon the homogeneous charge transport dynamics of the polymer. The large decrease in the measured $D_{C T}$ value upon going from $1.0 \mathrm{M}$ to $0.1 \mathrm{M} \mathrm{KNO}_{3}$, points to the passage of the charge compensating nitrate anion, into the polymeric matrix, as being the rate limiting step for the redox switching of the P4Os film in aqueous electrolyte. This type of situation has 
been observed before for Os redox polymers [11]. In addition the measured $\sqrt{D_{C T}} C$ and respective $D_{C T}$ values for the $\mathrm{P} 4 \mathrm{O}$ s polymer are an order of magnitude smaller than conducting polymers that contain "in-chain metal centres" [6] but higher than those polymers that contain metal centres linked to the polymer backboine via "non-conjugated" moieties [11]

\subsection{Conclusion}

The electrochemical behaviour of an $\mathrm{Os}^{2+}$ conjugated polymer, $\mathrm{P} 4 \mathrm{O}$ s, in aqueous electrolyte has been investigated. P4Os films on carbon electrodes were found to exhibit a one-electron reversible redox wave in aqueous solution due to the redox switching of the $\mathrm{Os}^{2+}$ centre. Initial investigations into the homogenous charge transport dynamics of this film in aqueous electrolyte have been undertaken. 


\section{References}

[1]. W. B. Euler, Polyhedron 10 (1991) 859.

[2]. K. D. Ley, K. A. Walters, K. S. Schanze, Synthetic Met. (1999) 1585.

[3]. W. Y. Ng, W. K. Chan, Adv. Mater. 9 (1997) 716.

[4]. S. S. Zhu, T. M. Swager, J. Am. Chem. Soc. 119 (1997) 12568.

[5]. G. Zotti, G. Schiavon, S. Zecchin, A. Berlin, G. Pagani, A. Canavesi, Synth. Met. 76 (1996) 255.

[6]. J. Hjelm, R. W. Handel, A. Hagfeldt, E. C. Constable, C. E. Housecroft, R. J. Forster. J. Phys. Chem. B. 107 (2003) No. 38, 10431.

[7] L. Trouillet, A. De Nicola, S. Guillerez, Synth. Met. 102 (1999) 1474.

[8]. K. A. Walters, L. Trouillet, S. Guillerez, K.S. Schanze, Inorg. Chem. 39 (2000) 5496.

[9] S. Guillerez, M. Kalaji, F. Lafolet, D. Novaes Tito, J. Electroanal. Chem. 563 (2004) 161.

[10] R. J. Forster, L. Keane, J. Electroanal. Chem., 554-555 (2003) 345.

[11] R. J. Foster, J. G. Vos, J. Electroanal. Chem., 314 (1991) 135. 
Table 1: Electrochemical parameters $\left(E_{p, a}, E_{p, c}, E_{1 / 2}, \Delta E_{p}\right)$ for a $P 4 O$ s film in $1.0 M N^{2} N_{3}$ as a function of scan rate.

\begin{tabular}{|c|c|c|c|c|}
\hline $\begin{array}{c}\text { Scan rate } \\
\left(\mathrm{V} \mathrm{s}^{-1}\right)\end{array}$ & $\begin{array}{c}\mathrm{E}_{\mathrm{p}, \mathrm{a}} \\
\left.\text { (volts vs. } \mathrm{Ag}^{+} / \mathrm{Ag}\right)\end{array}$ & $\begin{array}{c}\mathrm{E}_{\mathrm{p}, \mathrm{c}} \\
\text { (volts vs. } \mathrm{Ag}^{+} / \mathrm{Ag} \text { ) }\end{array}$ & $\begin{array}{c}\mathrm{E}_{1 / 2} \\
\left.\text { (volts vs. } \mathrm{Ag}^{+} / \mathrm{Ag}\right)\end{array}$ & $\begin{array}{c}\Delta \mathrm{E}_{\mathbf{p}} \\
\text { (millivolts) }\end{array}$ \\
\hline 0.1 & 0.890 & 0.819 & 0.855 & 71 \\
0.3 & 0.890 & 0.817 & 0.854 & 73 \\
0.5 & 0.886 & 0.817 & 0.852 & 69 \\
0.7 & 0.884 & 0.815 & 0.850 & 69 \\
& & & & \\
\hline
\end{tabular}




\section{Figure Legends}

Figure 1 Structure of the P4Os polymer where M stands for $\mathrm{Os}^{2+}$ and $\mathrm{n}=4$.

Figure 2(a) Cyclic voltammogram of a P4Os film on a glassy carbon electrode $\left(A=0.0707 \mathrm{~cm}^{2}\right)$ in a $0.1 \mathrm{M}$ TBAP MeCN solution between +0.45 and $+0.92 \mathrm{~V}$. Scan rate $=100 \mathrm{mV} \mathrm{s}^{-1}$.

Figure 2(b) Cyclic voltammogram of a P4Os film on a glassy carbon electrode $\left(A=0.0707 \mathrm{~cm}^{2}\right)$ in a $0.1 \mathrm{M}$ TBAP MeCN solution between 0 and $+1.25 \mathrm{~V}$. Scan rate $=100 \mathrm{mV} \mathrm{s}^{-1}$.

Figure 2(c) Cyclic voltammogram of a P4Os film on a glassy carbon electrode $\left(A=0.0707 \mathrm{~cm}^{2}\right)$ in a $0.1 \mathrm{M}$ TBAP MeCN solution between 0 and $+1.25 \mathrm{~V}$. Scan rate $=100 \mathrm{mV} \mathrm{s}^{-1}$.

Figure 3 Spectroelectrochemical Spectra of a P4Os film in $1 \mathrm{M} \mathrm{NaNO}_{3}$ at $\mathrm{OV}(-)$ and $+1.1 \mathrm{~V}(-)$

Figure 4(a) Cyclic voltammogram of a P4Os film coated on a 50 $\mu$ m radius platinum microelectrode in $1.0 \mathrm{M} \mathrm{KNO}_{3}$. Scan rates are 0.15 (inner curve), 0.3, 0.5 and $0.7 \mathrm{Vs}^{-1}$.

Figure 4(b) Randles-Sevcik Plot for P4Os in 1.0M $\mathrm{LiClO}_{4}$ 
Figure 1

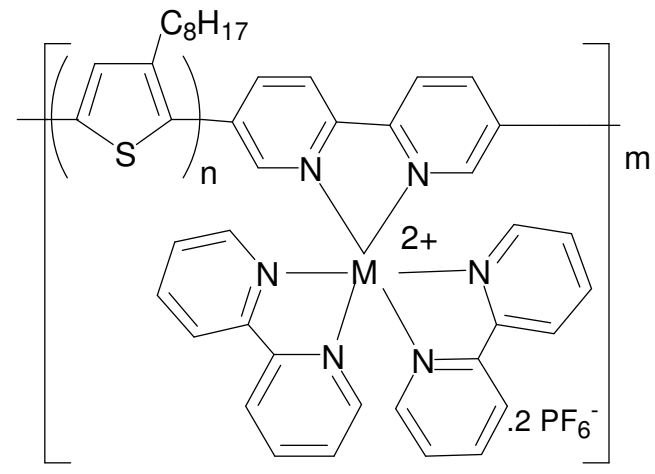


Figure 2(a)

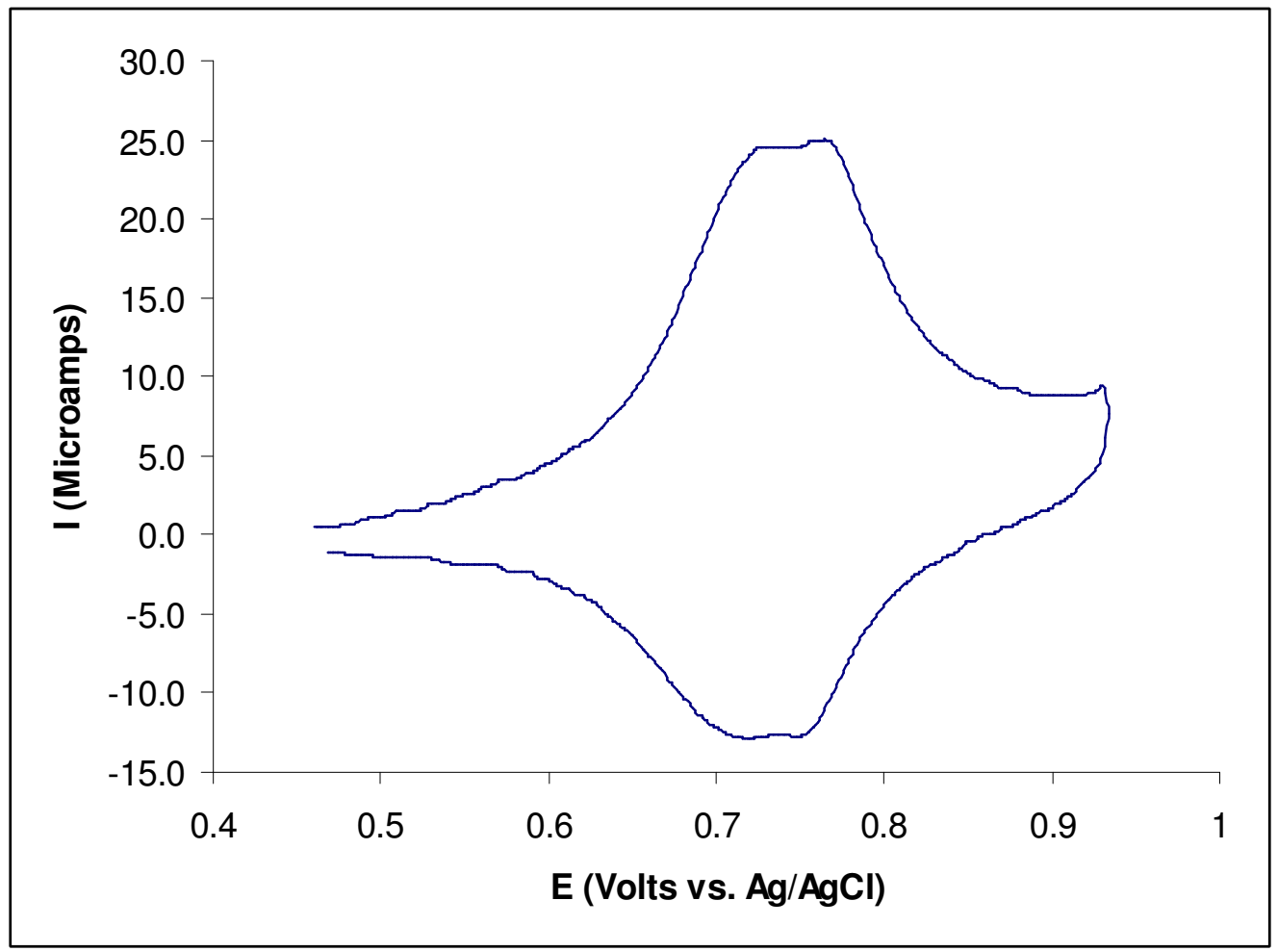


Figure 2(b)

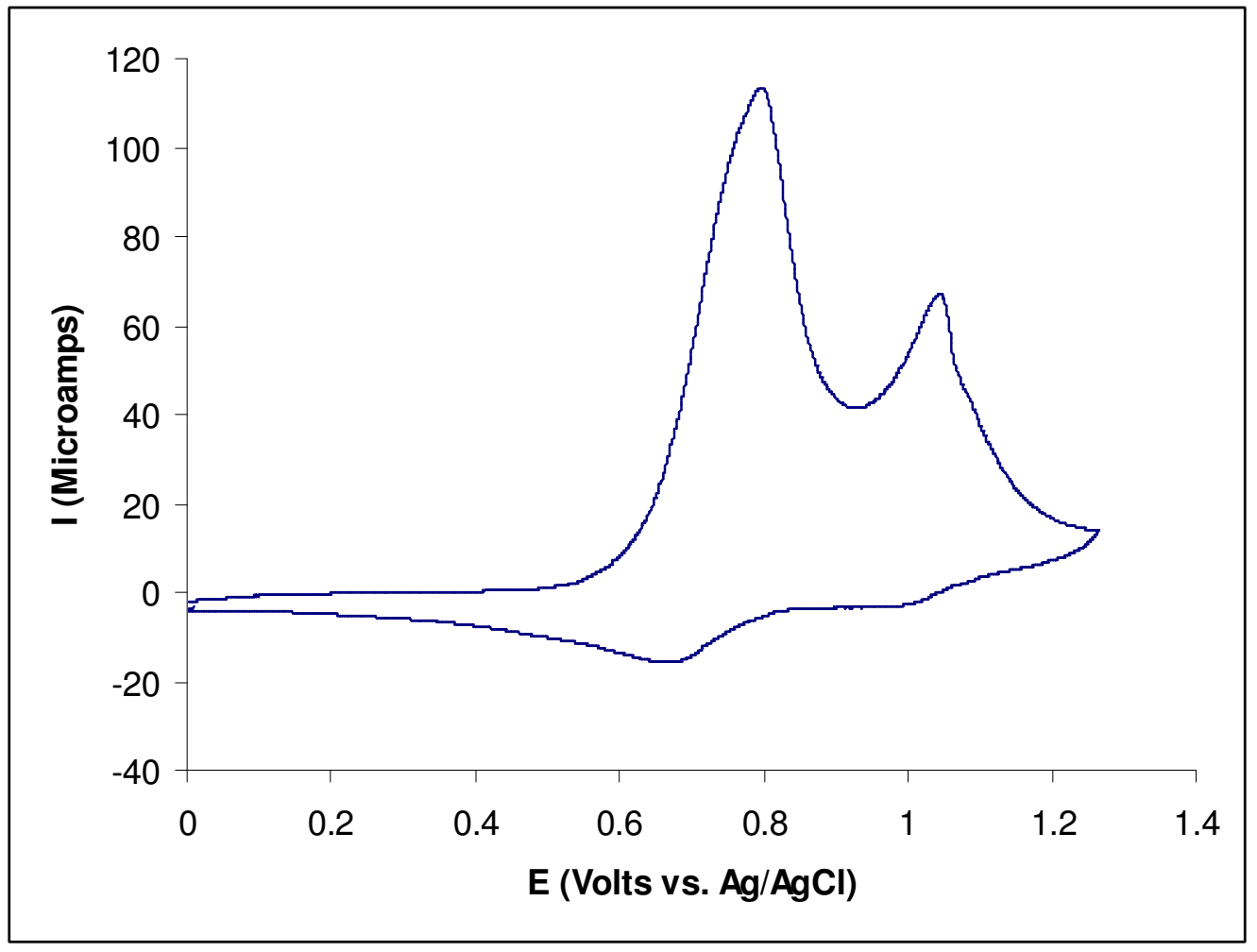


Figure 2(c)

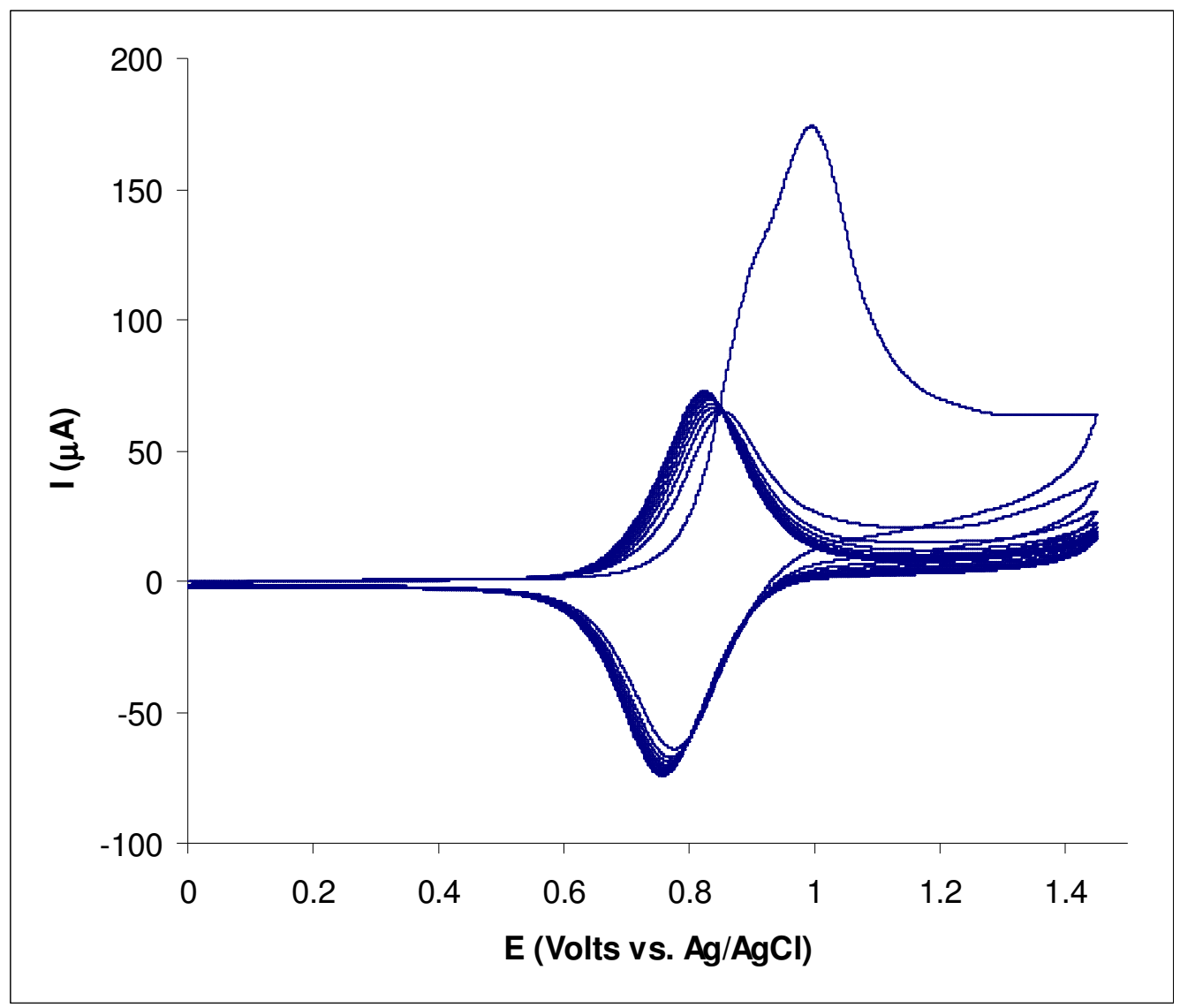


Figure 3

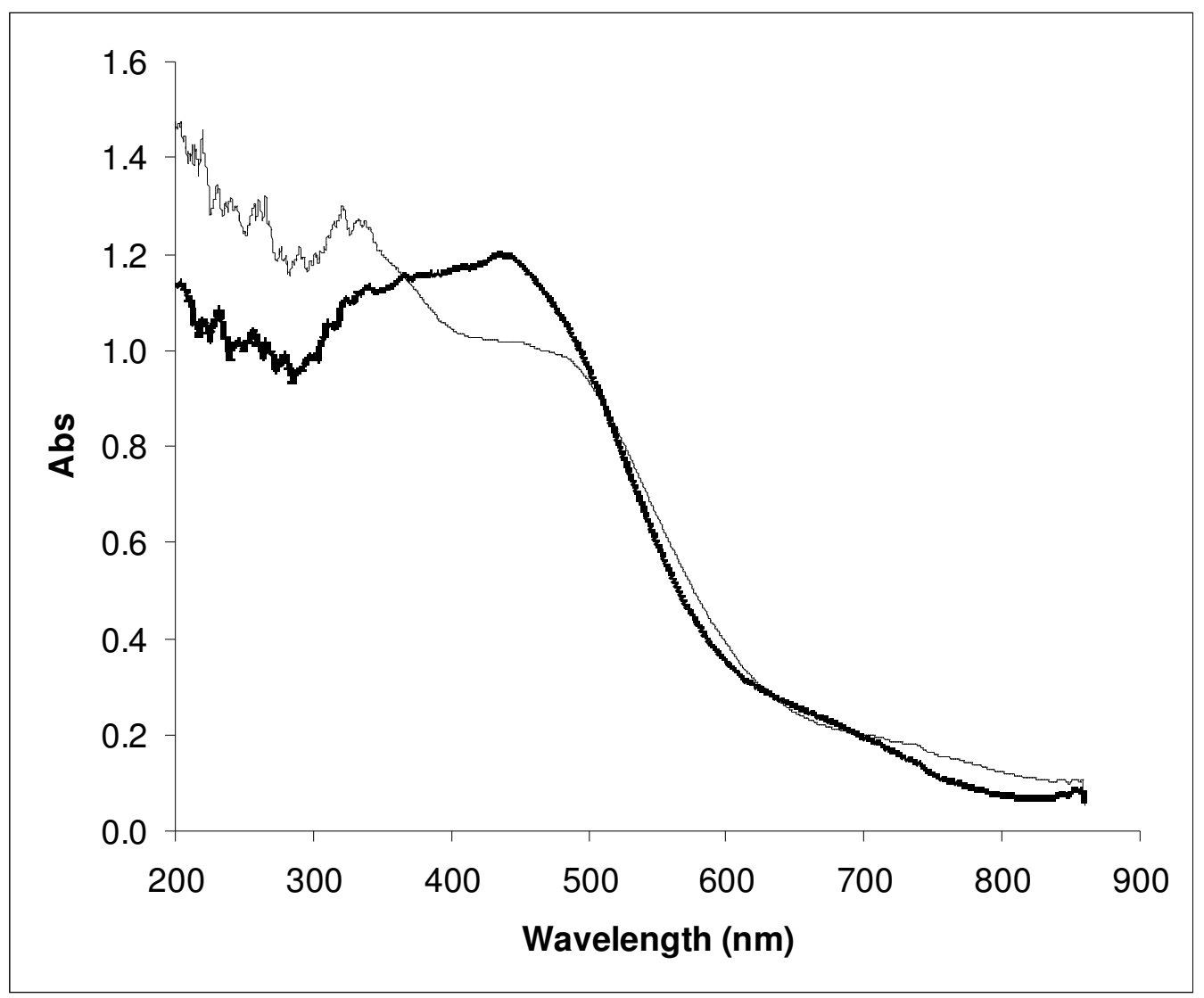


Figure 4(a)

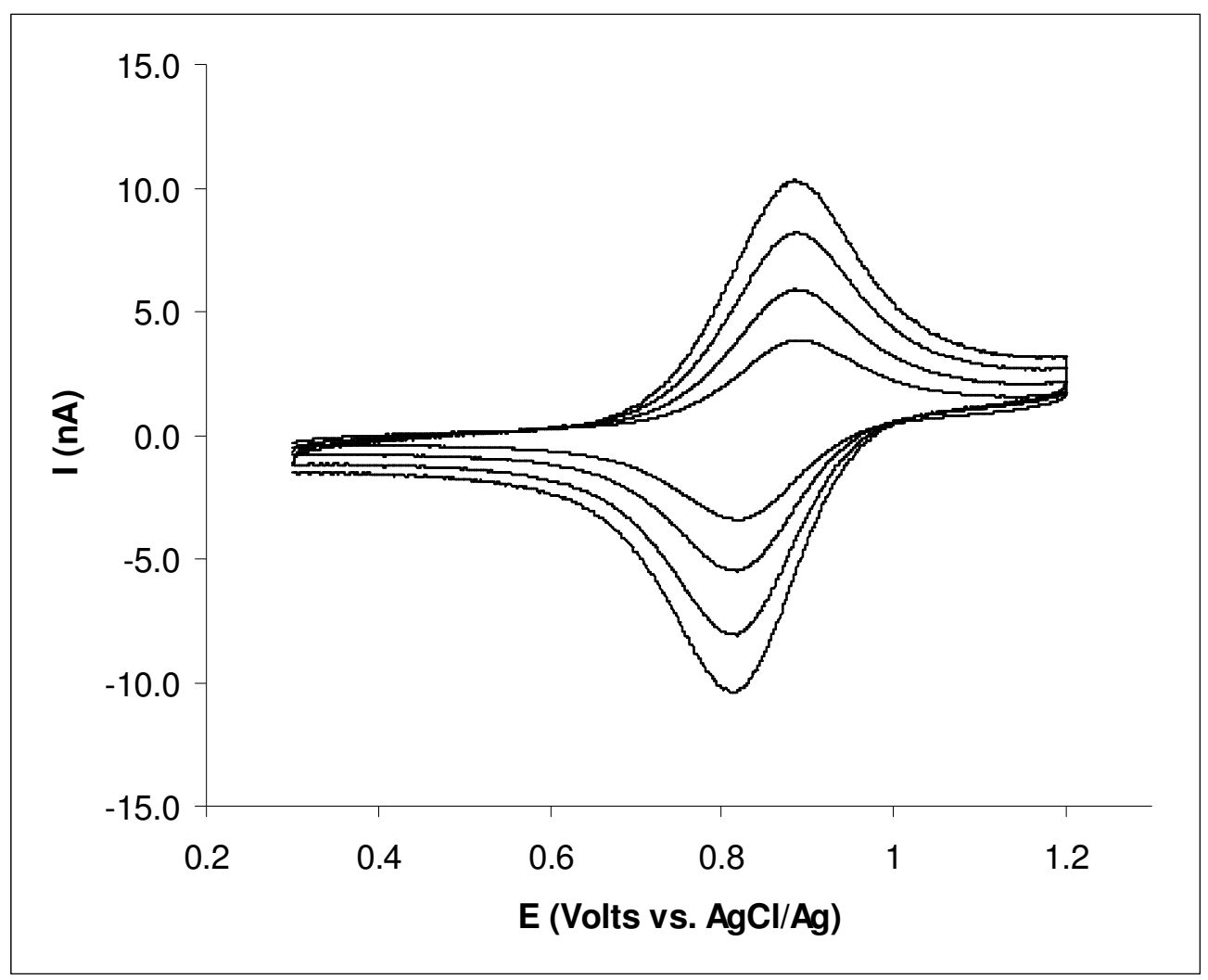


Figure 4(b)

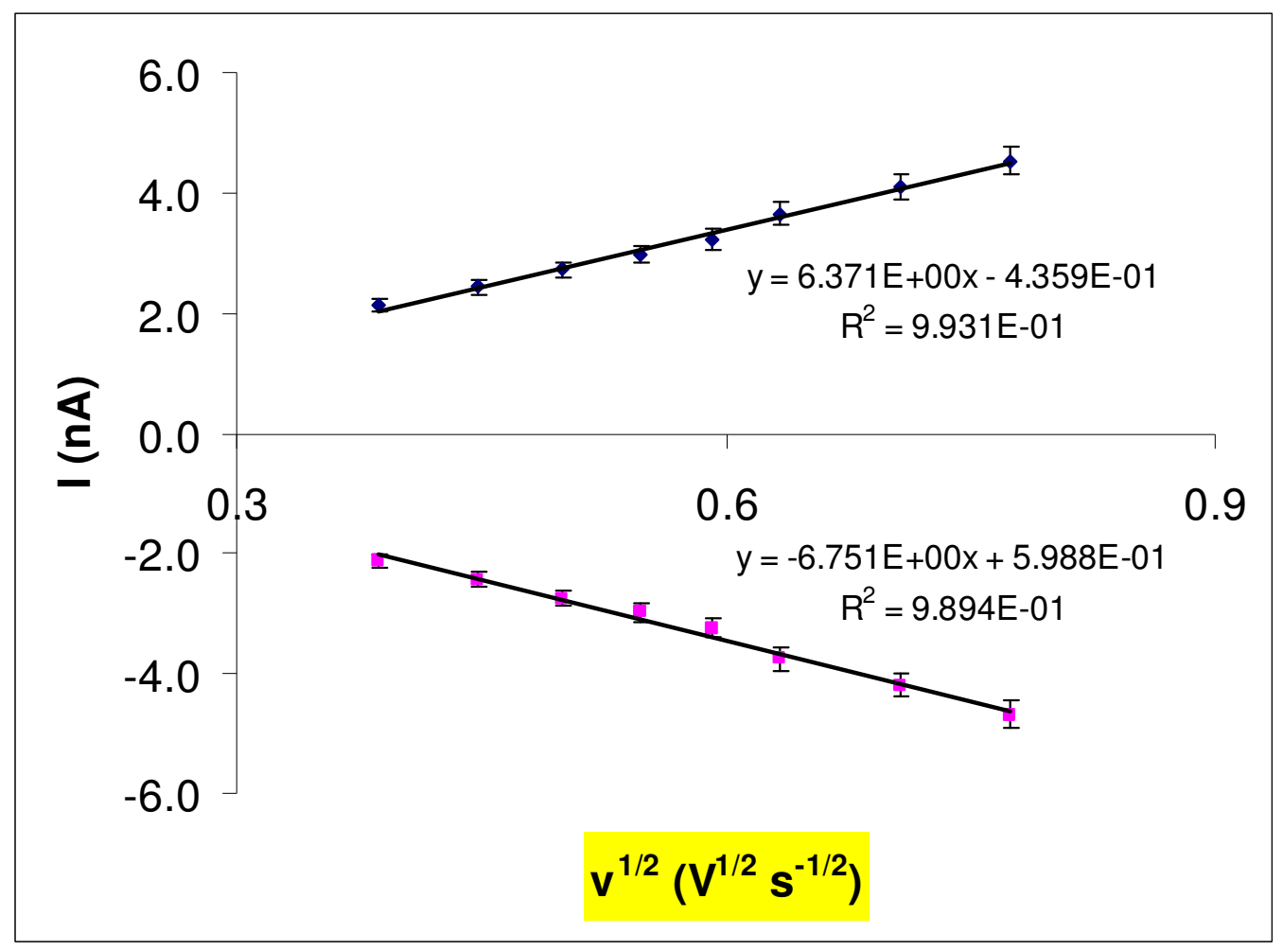


